\title{
The prevalence of Listeria species in different food items of animal and plant origin in Ethiopia: a systematic review and meta-analysis
}

\author{
Kuma Diriba ${ }^{* *} \mathbb{0}$, Ephrem Awulachew ${ }^{1}$ and Kuma Diribsa ${ }^{2}$
}

\begin{abstract}
Background: Listeriosis is one of the important emerging zoonotic disease affecting human health following the consumption of contaminated food of animal origin. It results in serious clinical complications in humans with a high case facility rate. Therefore, this systematic review and meta-analysis aimed to estimate the pooled prevalence of Listeria species in Ethiopia.

Methods: A systematic search was conducted on PubMed, Web of Science, EMBASE, Google Scholar and the Cochrane Library. All identified observational studies reporting the prevalence of Listeria species in different food items of animal and plant origin in Ethiopia were included. Three authors independently extracted data and analyzed them using STATA Version 13 statistical software. A random effects model was computed to estimate the pooled prevalence of Listeria species in Ethiopia.

Results: After reviewing 122 studies, five studies fulfilled the inclusion criteria were included in the meta-analysis. The findings from the five studies revealed that the pooled prevalence of Listeria species in different food items of animal and plant origin in Ethiopia was $27 \%(95 \% \mathrm{Cl} 25,29)$. The highest prevalence of Listeria species was reported in beef meat followed by ice cream with prevalence rates of $62 \%(95 \% \mathrm{Cl} 50,75)$ and $43 \%(95 \% \mathrm{Cl} 33,53)$, respectively.

Conclusion: The presence of Listeria species in different food items of animal and plant origin in Ethiopia is an indicator of the presence of public health hazards to the consumer, particularly to the high-risk groups. Hence, awareness creation on food safety and implementation of regulations is strongly recommended.
\end{abstract}

Keywords: Listeria, Prevalence, Milk products, Animal product, Ethiopia

\section{Background}

Listeriosis is an important emerging zoonotic disease affecting human health following the consumption of contaminated foods of animal origin [1]. Among the different species of the genus Listeria, L. monocytogenes is the causative agent of listeriosis [2]. L. monocytogenes

*Correspondence: kumadiriba47@gmail.com

${ }^{1}$ Department of Medical Laboratory Sciences, Health Science and Medical College, Dilla University, Dilla, Ethiopia

Full list of author information is available at the end of the article can persist for long periods in the environment or as an asymptomatic infection in adult animals and birds due to its psychrophilic nature, it can grow within a wide range of temperatures $\left(-1.5\right.$ to $\left.50{ }^{\circ} \mathrm{C}\right)$ [3]. L. monocytogenes can persist for long periods in the environment and can easily contaminate agricultural products and ultimately livestock products [4].

Listeria monocytogenes is an important cause of diseases in both animals and humans. In the vast majority of human cases, infection is the result of consumption

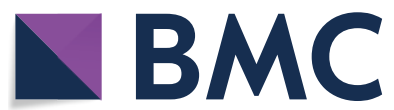

(c) The Author(s) 2021. This article is licensed under a Creative Commons Attribution 4.0 International License, which permits use, sharing, adaptation, distribution and reproduction in any medium or format, as long as you give appropriate credit to the original author(s) and the source, provide a link to the Creative Commons licence, and indicate if changes were made. The images or other third party material in this article are included in the article's Creative Commons licence, unless indicated otherwise in a credit line to the material. If material is not included in the article's Creative Commons licence and your intended use is not permitted by statutory regulation or exceeds the permitted use, you will need to obtain permission directly from the copyright holder. To view a copy of this licence, visit http://creativeco mmons.org/licenses/by/4.0/. The Creative Commons Public Domain Dedication waiver (http://creativecommons.org/publicdomain/ zero/1.0/) applies to the data made available in this article, unless otherwise stated in a credit line to the data. 
of contaminated food. L. monocytogenes is a food-borne pathogen, and its incidence and growth in food, contribute to outbreaks of listeriosis [5]. Reports have indicated that Listeria spp. including L. monocytogenes is most frequently prevalent in the milk-processing environment including steps, drains and floors [2]. In addition, different studies [6-8] reported that a higher prevalence of Listeria species was also found in meat and meat product foods, and ice cream samples.

The occurrence of listeriosis among humans has received increasing attention as epidemic listeriosis has been recognized and reported in immunosuppressed populations [9]. This bacterium principally causes intrauterine infection, meningitis and septicemia. Listeriosis in pregnancy may be asymptomatic or manifest as severe systemic infection in the unborn or newly delivered infants. The microorganism causes fatal infections such as encephalitis, sepsis and meningitis in immune deficient patients and abortion in pregnant women [10]. The mortality rate is reported to be $20-30 \%[11,12]$.

Currently, there is inadequate information regarding the prevalence of Listeria species in Ethiopia. Therefore, the present systematic review was undertaken to determine the pooled prevalence of Listeria species using a published article in Ethiopia.

\section{Methods}

\section{Study design}

A systematic review and meta-analysis were conducted to estimate the magnitude of Listeria species in different food items of animal and plant origin in Ethiopia following the methodological framework of systematic review and by checking the following five steps: step 1: framing questions for a review, step 2: identifying relevant work, step 3: assessing the quality of studies, step 4: summarizing the evidence, and step 5: interpreting the findings [13].

\section{Search strategies}

All relevant articles were searched using the following databases: PubMed, Web Science, Embase, Google Scholar, Cochrane Library and Science Direct according to the Preferred Reporting Items for Systematic Reviews and Meta-analysis (PRISMA) [14]. All searches were limited to articles written in English given that such language restriction does not alter the outcome of the systematic reviews and meta-analysis [15]. The gray literature of observational studies was searched through the review of reference lists and input of content experts. The literature search was conducted from January 2009 to February 2015. All papers published until the end of 2015 and fulfilling inclusion criteria were considered. The search used the following keywords "listeria", "prevalence", "milk products", "animal product", and "Ethiopia “. The search terms were used separately and in combination using Boolean operators such as "OR" or "AND".

\section{Eligibility criteria}

Studies conducted only in Ethiopia and involving only humans were included in this study. Publication condition: only published articles were included. Study design: all observational study designs reporting the prevalence of Listeria species in animal and plant product were eligible for this review. Language: only articles reported in the English language were considered. Exclusion criteria: articles, that were not fully accessible, after email contact with the primary authors and duplicate publications of the same study, were excluded.

\section{Assessment of study quality}

Studies selected for inclusion were assessed for methodological quality by all authors independently using the standard critical appraisal instruments of the Joanna Briggs Institute Meta-analysis of Statistics Assessment for Review Instrument (JBI-MAStARI) [16]. Disagreements were resolved by consensus.

\section{Outcome measure}

The primary outcome variable of this study was the prevalence of Listeria species, while the secondary outcome was its comparison in different types of food, including cheese, raw beef, raw milk, fish meat, raw meat, ice cream, and cream cake.

\section{Data extraction}

Data were extracted using a standardized data extraction format, adapted from the Joanna Briggs Institute (JBI), by three authors (Kuma Diriba, Ephrem Awulachew and Kumsa Diriba) independently extracting all necessary data. Then, the extracted data were merged for systematic analysis. Any disagreements during the data extraction were resolved through discussion and consensus. The main outcomes extracted from the study were: primary author, publication year, study method, study area, sample size and cases. Data on associated risk factors were also extracted by the authors.

\section{Statistical analysis}

Following data extraction, systematic review and metaanalysis were carried out using $\mathrm{R}$ software version 3.6.1 and STATA statistical software (version 13) with user contributed commands for meta-analyses: metaprop, metan, metainf, metabias, and metareg [17]. The effect sizes and SEs of the studies were pooled using a randomeffects model to calculate the pooled prevalence of Listeria species in different food items of animal and plant 
origin in Ethiopia. A meta-analysis was also planned to assess the association Listeria species in different food items of animal and plant origin collected during the study period.

The standard error for each original study was calculated using the binomial distribution formula. Evidence for statistical heterogeneity among reported prevalence was using the Cochrane Q-test and $I^{2}$ statics [18]. The pooled proportion was estimated using the backtransform of the weighted mean of the transformed proportions for both the fixed-effects model and the random-effects model [19]. A significance level of $P<0.10$ and $I^{2}>50 \%$ was interpreted as evidence of heterogeneity [20]. A potential source of heterogeneity was investigated by subgroup analysis and meta-regression analysis [21]. Where statistical pooling was not possible, the findings were presented in a narrative form including tables and figures to aid in data presentation where appropriate.

\section{Risk of bias}

Three authors (KD, EA and KD) independently assessed the risk of bias for each original study using the 10 criteria tool of Hoy 2012 which addresses internal and external validity [55]. The tool mainly included [1] representation of the population, [2] sampling frame, [3] methods of participants' selection, [4] non-response bias, [5] data collection directly from subjects, [6] acceptability of case definition, [7] reliability and validity of study tools, [8] mode of data collection, [9] length of prevalence period, and [10] appropriateness of numerator and denominator. Each item was classified as either low or high risk of bias. Finally, the overall score of risk of bias was then categorized into low [2], moderate [3, 4], and high $(>5)$ out of 10 and almost all of the original study fall under low risk of bias.

Sensitivity analyses were conducted to weigh up the relative influence of each individual study on the pooled effect size using a user-written function, metainf. The presence of publication bias was assessed informally by visual inspection of funnel plots [22]. Point prevalence, as well as $95 \%$ confidence intervals, was presented in the forest plot format.

\section{Results}

\section{Study selection}

Data base search identified a total of 122 articles reporting prevalence of Listeria species in different food items of animal and plant origin. From these initial articles, 40 articles were excluded due to duplication. From the remaining 82 articles, 51 articles were excluded after review of their titles and abstracts confirmed non-relevance to this review, 31 full-text articles were assessed with respect to their eligibility for inclusion, which resulted in the further exclusion of 26 articles primarily due to the study done in other countries [23-49], and 5 studies were included in the final systematic review and meta-analysis (Fig. 1).

\section{Description of included studies}

In this review, the five papers published between, 2009 and 2015 and reported prevalence of Listeria species in different food items of animal and plant origins were included. In this systematic review and meta-analysis, 2169 study participants were included to assess the pooled prevalence of Listeria species among food and animals products. Sample size of the included studies was ranged from 240 to 711 . The prevalence of Listeria species in different areas reported in this meta-analysis was near to each other with the lowest prevalence (25\%) reported in in Gondar town, Amhara [50] and the highest prevalence (28\%) in Addis Ababa [51, 52]. Three of the studies were from Addis Ababa [51-53], and two from Amhara $[6,50]$ (Table 1).

\section{Risk of bias}

The risk of bias tool [55] was used to assess the risk of bias for the included studies and almost greater than $80 \%$ of the studies had low risk of bias. The sample selection and temperature during transport and the amount of any individual sample tested were specified in some of the studies. Listeria specific enrichment media, biochemical test and supplement were used in majority of the studies. Listeria was incubated at $30{ }^{\circ} \mathrm{C}$ for $24-48 \mathrm{~h}$ in most of the studies.

\section{The magnitude of Listeria species in Ethiopia}

The pooled prevalence of Listeria species in different food items of animal and plant origin in Ethiopia was $27 \%(95 \%$ CI 25,29$)$. The heterogeneity observed across the included studies was zero $\left(I^{2}=0, p=0.84\right)$. From this meta-analysis, the prevalence of each study was nearer to each other falling within the range of $25 \%$ and 28\% (Fig. 2).

Based on our finding, there are about seven species of listeria commonly reported throughout the country from which $L$. ivanovii was the predominant listeria isolate followed by $L$. welshimeri with prevalence of 149 $(29.7 \%)$ and 147 (29.3\%), respectively. The highest prevalence of L. monocytogenes was reported in study conducted in Gondar town [6] with prevalence of $32.7 \%$, while $L$. seeligeri was the least listeria isolate with prevalence of 14 (2.8\%) (Table 2). 


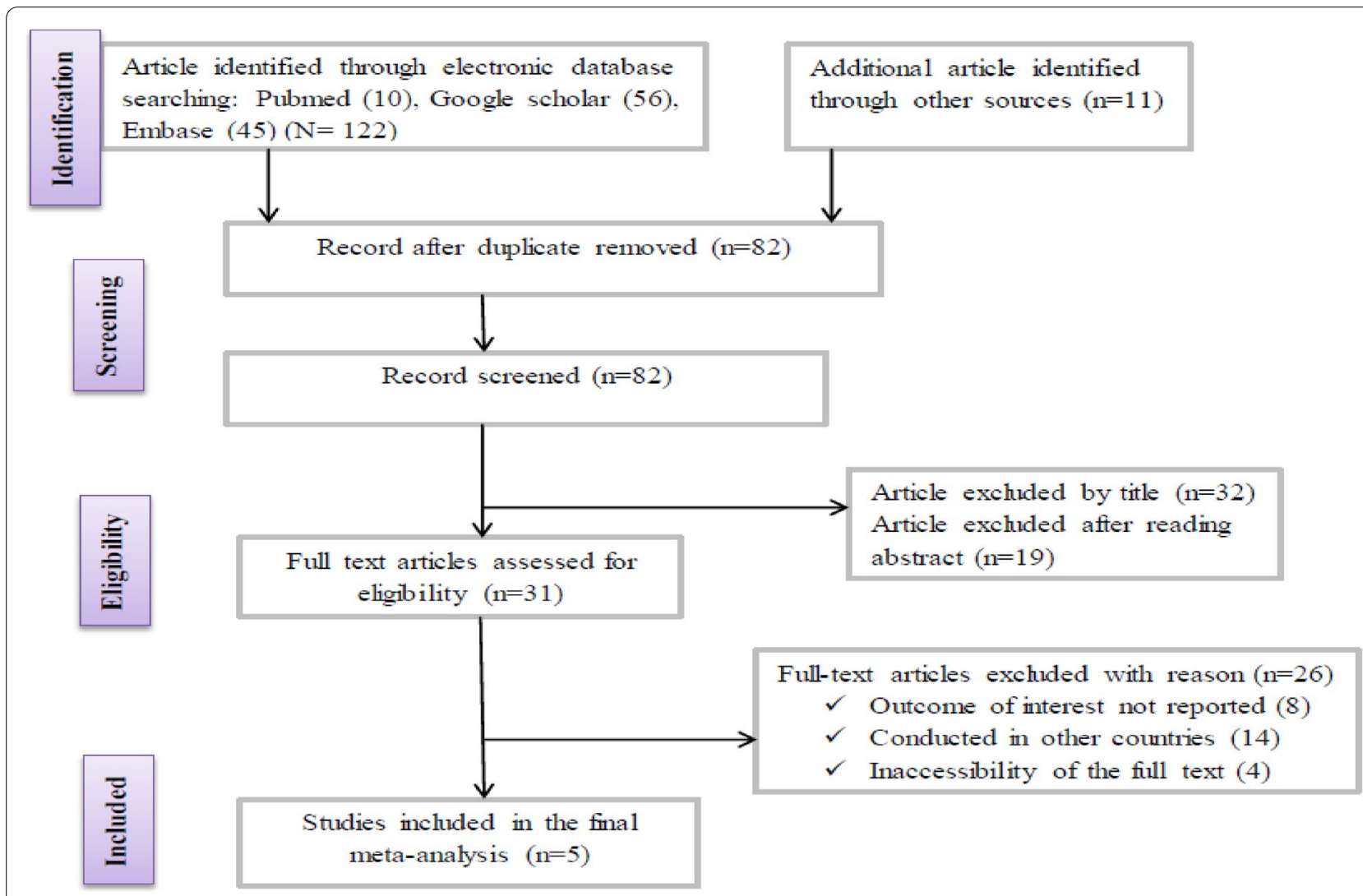

Fig. 1 Flow chart of study selection for systematic review and meta-analysis of the prevalence of Listeria species in different food items of animal and plant origin

Table 1 Description of five studies included in the meta-analysis of the prevalence of Listeria species in different food items of animal and plant origin in Ethiopia, 2020

\begin{tabular}{|c|c|c|c|c|c|c|c|}
\hline First authors & Publication year & Study method & Study area & Region & Sample size & Cases & $\begin{array}{l}\text { Prevalence } \\
\text { with } 95 \% \\
\mathrm{Cl}\end{array}$ \\
\hline Mengesha et al. [6] & 2009 & Cross-sectional & Gondar town & Amhara & 711 & 189 & $27(23,30)$ \\
\hline Seyoum et al. [51] & 2015 & Cross-sectional & Addis Ababa & Addis Ababa & 443 & 126 & $28(24,33)$ \\
\hline Derra et al. [52] & 2013 & Cross-sectional & Addis Ababa & Addis Ababa & 240 & 66 & $28(22,34)$ \\
\hline Kebede et al. [53] & 2010 & Cross-sectional & Addis Ababa & Addis Ababa & 391 & 102 & $26(22,31)$ \\
\hline Garedew et al. [54] & 2015 & Cross-sectional & Gondar town & Amhara & 384 & 96 & $25(21,30)$ \\
\hline
\end{tabular}

\section{Prevalence of Listeria species in different food items of animal and plant origin in different study area in Ethiopia}

In this systematic review and meta-analysis, we tried to assess the distribution of Listeria species in different food items of animal and plant origin. The highest and the lowest contamination of Listeria species was reported from Gondar town with highest prevalence $28 \%$ [54] and the lowest prevalence $0.0 \%$ [6] which may be due to study period. The highest prevalence of Listeria species in beef meat was reported in Addis Ababa [52] with prevalence of $62 \%$, but the lowest prevalence was reported in Gondar town [54] with a rate of $24 \%$. Higher prevalence of Listeria species in cream (43\%) and in egg (32\%) was reported in Amhara region [6] and Addis Ababa [51], respectively. However, the lowest prevalence of Listeria species in cream (23\%) and egg (16\%) was reported in Addis Abba [52] and Gondar town [6], respectively (Table 3). 


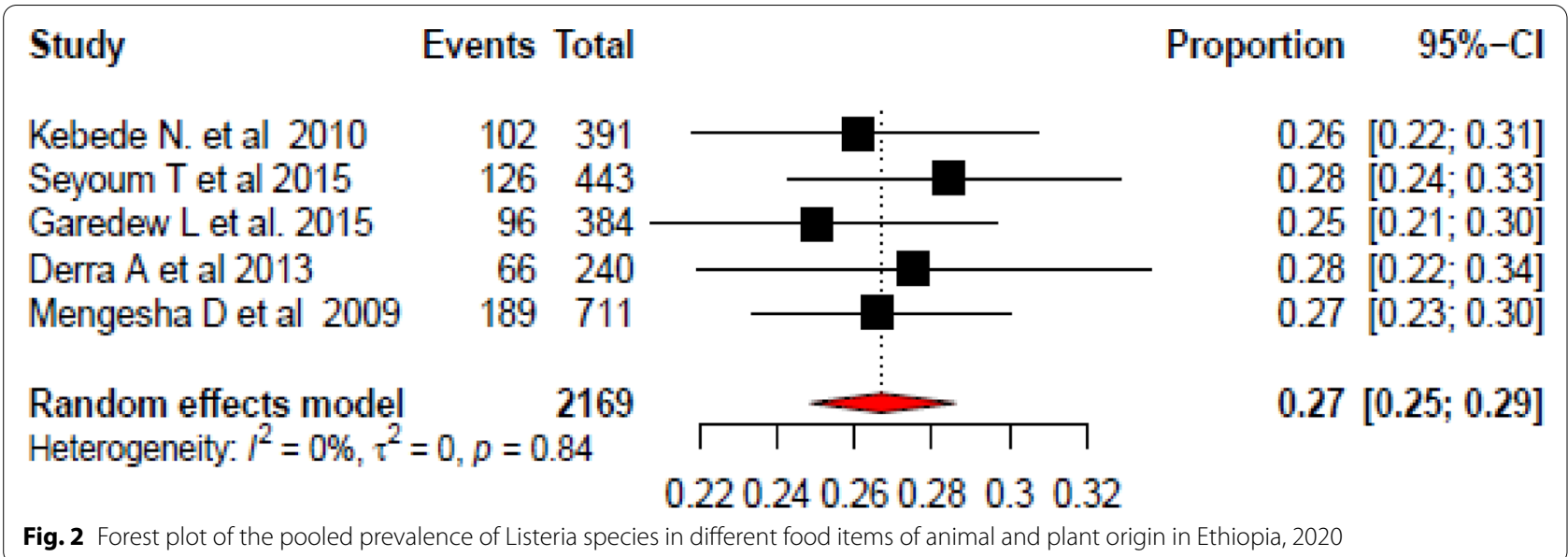

Table 2 Prevalence of listeria species in different study area found in Ethiopia, 2020

\begin{tabular}{llccccccc}
\hline Author & Study area & L. monocytogenes & L. ivanovii & L. innocua & L. seeligeri & L. welshimeri & L. grayi & L. murrayi \\
\hline Mengesha et al. [6] & Gondar town & $34(32.7 \%)$ & $126(84.6 \%)$ & $4(2.7 \%)$ & $5(35.7 \%)$ & $13(37.1 \%)$ & $1(4 \%)$ & $6(22.2 \%)$ \\
Seyoum et al. [51] & Addis Ababa & $25(24 \%)$ & $19(12.8 \%)$ & $33(22.4 \%)$ & $12(85.7 \%)$ & $6(17.1 \%)$ & $19(76 \%)$ & $12(44.4 \%)$ \\
Kebede et al. [53] & Jimma town & $21(20.2 \%)$ & $2(1.3 \%)$ & $62(42.2 \%)$ & $4(28.6 \%)$ & $7(20 \%)$ & $3(12 \%)$ & $3(11.1 \%)$ \\
Garedew et al. [54] & Gondar town & $24(23.1 \%)$ & $2(1.3 \%)$ & $48(32.7 \%)$ & $5(35.7 \%)$ & $9(25.7 \%)$ & $2(8 \%)$ & $6(22.2 \%)$ \\
Pooled prevalence of each species & $104(20.8 \%)$ & $149(29.7 \%)$ & $147(29.3 \%)$ & $14(2.8 \%)$ & $35(7.0 \%)$ & $25(5.0 \%)$ & $27(5.4 \%)$ \\
\hline
\end{tabular}

Table 3 Magnitude of Listeria species in different food items of animal and plant origin in Ethiopia, 2019

\begin{tabular}{|c|c|c|c|c|c|c|c|c|}
\hline Author & Year & Region & Study area & $\begin{array}{l}\text { Cheese } P(95 \% \\
\text { Cl) }\end{array}$ & $\begin{array}{l}\text { Beef meat } P \\
(95 \% \mathrm{Cl})\end{array}$ & $\begin{array}{l}\text { Raw milk } P(95 \% \\
\text { CI) }\end{array}$ & $\begin{array}{l}\text { Cream } P(95 \% \\
\text { Cl) }\end{array}$ & $\operatorname{Egg} P(95 \% \mathrm{Cl})$ \\
\hline $\begin{array}{l}\text { Mengesha et al. } \\
{[6]}\end{array}$ & 2009 & Amhara & Gondar town & $0(0,7)$ & $48(38,57)$ & $0(0,7)$ & $43(33,53)$ & $16(11,22)$ \\
\hline Seyoum et al. [51] & 2015 & Addis Ababa & Addis Ababa & $21(17,26)$ & ND & $21(17,26)$ & ND & $32(24,42)$ \\
\hline Derra et al. [52] & 2013 & Addis Ababa & Addis Ababa & $10(3,24)$ & $62(50,75)$ & $10(3,24)$ & $23(13,34$ & ND \\
\hline Kebede et al. [53] & 2014 & Oromia & Jimma Town & $22(14,31$ & $51(40,63)$ & $22(14,31)$ & ND & ND \\
\hline $\begin{array}{l}\text { Garedew et al. } \\
\text { [54] }\end{array}$ & 2015 & Amhara & Gondar town & $28(16,42)$ & $24(9,45)$ & $28(16,42)$ & $23(15,34)$ & ND \\
\hline Pooled prevalence & & & & $10(6,16)$ & $4837,60)$ & $13(5,29)$ & $29(20,41)$ & $23(13,36)$ \\
\hline
\end{tabular}

ND not done in original article; $P(95 \% \mathrm{Cl})$ prevalence with $95 \%$ confidence interval

\section{The distribution of Listeria species in different food items} of animal and plant origin

Regarding their distribution in different food item, $L$. innocua was the leading isolate in cheese with prevalence of $52.9 \%$, followed by L.monocytogenes (17.8\%) and L. murrayi (11.8\%). L. innocua was the predominant isolated Listeria in raw beef, cream and egg with prevalence of $61.1 \%, 48.6 \%$ and $72 \%$, respectively, while L. grayi was the least isolate in raw beef and cream with prevalence ranged from 0.0 to $1.4 \%$ and $L$. murrayi was the least isolate in egg with prevalence of $0.0 \%$ (Table 4 ).

\section{Discussion}

Data on Listeria species in different food items of animal and plant origin in Ethiopia are limited and are not currently available in aggregate form. We conducted a systematic review and meta-analysis to provide the pooled prevalence of Listeria species in different food items of animal and plant origin. Listeria species are a leading cause of bacterial-derived foodborne disease worldwide with an estimated 400 million cases per year [56]. The information from this study might be used by the policy makers in the prevention and control of the infection. 
Table 4 Distribution of Listeria species in different food items of animal and plant origin (chees, raw beaf, raw milk, cream, egg) in Ethiopia, 2020

\begin{tabular}{|c|c|c|c|c|c|c|}
\hline Listeria species isolated & Cheese & Raw beef & Raw milk & Cream & Egg & Total \\
\hline L. monocytogenes & $9(17.6 \%)$ & $12(11.1 \%)$ & $22(25.6 \%)$ & $22(29.7 \%)$ & $8(16.0 \%)$ & $73(19.8 \%)$ \\
\hline L.ivanovii & $2(3.9 \%)$ & $12(11.1 \%)$ & $12(14.0 \%)$ & $8(10.8 \%)$ & $1(2.0 \%)$ & $35(9.5 \%)$ \\
\hline L. innocua & $27(52.9 \%)$ & $66(61.1 \%)$ & $11(12.8 \%)$ & $36(48.6 \%)$ & $36(72.0 \%)$ & $176(47.7 \%)$ \\
\hline L. seeligeri & $3(5.9 \%)$ & $3(2.8 \%)$ & $12(14.0 \%)$ & $1(1.4 \%)$ & $1(2.0 \%)$ & $20(5.4 \%)$ \\
\hline L. welshimeri & $2(3.9 \%)$ & $14(13.0 \%)$ & $4(4.7 \%)$ & $2(2.7 \%)$ & $2(4.0 \%)$ & $24(6.5 \%)$ \\
\hline L. grayi & $2(3.9 \%)$ & $0(0.0 \%)$ & $18(20.9 \%)$ & $1(1.4 \%)$ & $2(4.0 \%)$ & $23(6.2 \%)$ \\
\hline L. murrayi & $6(11.8 \%)$ & $1(0.9 \%)$ & $7(8.1 \%)$ & $4(5.4 \%)$ & $0(0.0 \%)$ & $18(4.9 \%)$ \\
\hline Total & $51(13.8 \%)$ & $108(29.3 \%)$ & $86(23.3 \%)$ & $74(20.1 \%)$ & $50(13.6 \%)$ & $369(100 \%)$ \\
\hline
\end{tabular}

In the present study, the pooled prevalence of Listeria species in different food items of animal and plant origin obtained from this study was $27 \%$ that indicated significant public health hazard associated with consumption of contaminated foods of animal and plant origin. This indicates, in part, increased attention to the issues of microbial food safety in this region. The result of this meta-analysis is in line with study conducted in Malaysia [57], Chile [58], Uganda [59] and Botswana [60]. However, our result is higher than the study conducted in Ghana [61] and elsewhere [51] and lower than study conducted in Turkey [62] and Norway [63]. The possible explanation for the above variation may be methodological difference, differences in food items composition or hygienic status of different food items of animal and plant origin.

In the current study, both food items of animal and plant origin showed a significant level of contamination with Listeria species. In this study, cheese, raw beef, raw milk and liquid whole egg samples were collected and analyzed for the presence of $L$. monocytogenes and other Listeria species. Among the seven species of listeria reported in different research article conducted in Ethiopia, $L$. ivanovii was the predominant bacterium isolated followed by $L$. welshimeri with prevalence of $29.7 \%$ ) and $29.3 \%$, respectively. The finding of this study is consistent with studies done elsewhere [64-67]. The highest prevalence of $L$. monocytogenes was reported in study conducted in Gondar town with prevalence of $32.7 \%$. In this meta-analysis, L. seeligeri $(2.8 \%)$ was the least bacterium isolated from food items of animal and plant origin.

In the present meta-analysis, raw beef was found to be the predominant food item contaminated with Listeria species, including L. monocytogenes. Out of 369 food items of animal and plant origin examined, around one third (29.3\%) raw beef meat were contaminated with Listeria species, in which $L$. monocytogenes rated 11.1\%. L. innocua was the predominant Listeria species isolated from this food item by account $61.1 \%$ of the total listeria species. This finding is similar with study conducted elsewhere $[2,68,69]$. The high contamination of the beef samples may be due to poor hygienic conditions during slaughtering, processing and selling. This indicates raw or undercooked beef meat was consumed traditionally throughout the country which aggravates the public health associated to Listeria species. Further processing and handling of meat also increases the risk of contamination with Listeria species $[70,71]$.

Similarly, we identified a significant level of contamination of raw milk with Listeria species (23.3\%). L. monocytogenes the predominant bacterium isolated from raw milk with prevalence of $25.6 \%$ followed by $L$. welshimeri, L. seeligeri and L. ivanovii with prevalence ranged from 14 to $21 \%$. This is consistent with studies conducted in different areas $[60,72,73]$, where high contamination level of listeria species in milk and milk products identified. This high prevalence of listeria in milk might be due the tradition of mixing milk with water before selling to the consumer which increases the chances of contamination during dilution with water, poor personal hygiene or from contaminated environment and also poor milking practices [74].

In this meta-analysis, there was higher contamination of ice cream samples with L. innocua, L. monocytogenes and L. ivanovii with prevalence ranged from 10 to $47 \%$. This might be due to the properties of the ice cream that facilitate a suitable condition for listerial growth and multiplication [58]. The increased contamination ice cream might be due the nature of this bacteria that can withstand a wide range of wide temperatures and other factor like, water contamination, and poor hygienic quality of food items sold in the country The consumption of animal product can change the nature of this bacteria which may drive emergence of new epidemiological patterns of disease $[75,76]$. 


\section{Limitations of the study}

The collected article for this study was limited to English language. Study method (most them were cross-sectional), which can affect the outcome variable by other confounding variables. Small sample size, which could affect the estimated pooled prevalence of Listeria species in different food items of animal and plant origin. Therefore, this meta-analysis represented only studies reported from limited study area, which may reflect under-representation due to the limited number of studies included.

\section{Conclusion}

In this meta-analysis, there was high prevalence of $L$. monocytogenes and other Listeria species among different food items of animal and plant origin. In this study, L. innocua was predominantly isolated from cheese followed by L.monocytogenes and L. murrayi. L. innocua was the predominant isolated Listeria in raw beef, cream and egg, while L. grayi was the least isolate in raw beef and cream and L. murrayi was the least isolate in egg. Therefore, based on our findings, we recommend emphasis shall be given on health educations about cooking of animal product before consumption, improved food safety through the implementation of hygienic measures at all levels from production to consumption with particular emphasis on personal hygiene as well as, proper disposal of wastes including excreta in integration with the existing national health extension program are recommended.

\section{Acknowledgements \\ The authors would like to acknowledge Dilla University, Collage of health sci-} ence and medicine and department of medical laboratory science

\section{Authors' contributions}

$\mathrm{KD}$ is the first and corresponding author. KD and EA conceived and designed the study. KD, EA and KD acquired the data. KD and EA analyzed the data and interpreted the results. Both KD and EA drafted the initial and final manuscripts. Both KD and EA performed critical revisions of the manuscript. All authors read and approved the final manuscript.

\section{Funding}

The authors have not declared a specific grant for this research from any funding agency in the public, commercial or not-for-profit sectors.

\section{Availability of data and materials}

All data relevant to the study are included in the article.

\section{Declarations}

\section{Ethics approval and consent to participate}

Ethical approval was not required, because the analysis under consideration is from data that already publicly available in published studies.

\section{Consent for publication}

Not required.

\section{Competing interests}

The authors declare that they have no competing interests.

\section{Author details}

${ }^{1}$ Department of Medical Laboratory Sciences, Health Science and Medical College, Dilla University, Dilla, Ethiopia. ${ }^{2}$ Department of Biology, Educational College, Dilla University, Dilla, Ethiopia.

Received: 9 October 2020 Accepted: 14 June 2021

Published online: 24 June 2021

\section{References}

1. Van de Venter T, editor. Prospects for the future. Emerging problems: chemical/biological. Conference on international food trade beyond 2000: science-based decisions, harmonization, equivalence and mutual recognition, Melbourne (Australia), 11-15 Oct 1999; 1999.

2. Vitas A. Occurrence of Listeria monocytogenes in fresh and processed foods in Navarra (Spain). Int J Food Microbiol. 2004;90(3):349-56.

3. Ramaswamy V, Cresence VM, Rejitha JS, Lekshmi MU, Dharsana K, Prasad SP, et al. Listeria-review of epidemiology and pathogenesis. J Microbiol Immunol Infect. 2007:40(1):4

4. Auerbuch V, Brockstedt DG, Meyer-Morse N, O'Riordan M, Portnoy DA. Mice lacking the type I interferon receptor are resistant to Listeria monocytogenes. J Exp Med. 2004;200(4):527-33.

5. Jemmi T, Stephan R. Listeria monocytogenes: food-borne pathogen and hygiene indicator. Rev Sci Tech. 2006;25(2):571-80.

6. Mengesha D, Zewde BM, Toquin M-T, Kleer J, Hildebrandt G, Gebreyes WA. Occurrence and distribution of Listeria monocytogenes and other Listeria species in ready-to-eat and raw meat products. Berl Munch Tierarztl Wochenschr. 2009;122(1-2):20-4.

7. Abera F. Prevalence and antimicrobial profile of Listeria monocytogenes in retail meat and dairy products in Addis Ababa and its surrounding towns. Ethiopia: Addis Abeba university; 2007.

8. Kozačinski L, Hadžiosmanović M, Mioković B, Njari B, Pranjić D, Cvrtila Ž. The meaning of Listeria monocytogenes in veterinary-sanitary inspection. Veterinarski Arhiv. 2000:70:57-13.

9. Aureli P, Fiorucci GC, Caroli D, Marchiaro G, Novara O, Leone L, et al. An outbreak of febrile gastroenteritis associated with corn contaminated by Listeria monocytogenes. N Engl J Med. 2000;342(17):1236-41.

10. Mateus T, Silva J, Maia RL, Teixeira P. Listeriosis during pregnancy: a public health concern. ISRN Obste Gynecol. 2013;2013:1-6.

11. Wing EJ, Gregory SH. Listeria monocytogenes: clinical and experimental update. J Infect Dis. 2002;185(1):18-24.

12. Swaminathan B, Gerner-Smidt P. The epidemiology of human listeriosis. Microbes Infect. 2007;9(10):1236-43.

13. Arksey H, O'Malley L. Scoping studies: towards a methodological framework. Int J Soc Res Methodol. 2005:8(1):19-32.

14. Liberati A, Altman DG, Tetzlaff J, Mulrow C, Gøtzsche PC, loannidis JP, et al. The PRISMA statement for reporting systematic reviews and meta-analyses of studies that evaluate health care interventions: explanation and elaboration. PLoS Med. 2009:6(7):e1000100.

15. Moher D, Pham B, Lawson M, Klassen T. The inclusion of reports of randomised trials published in languages other than english in systematic reviews. Health Technol Assess. 2003;7(41):1-90.

16. Armstrong R, Waters E, Jackson N. Systematic reviews of health promotion and public health interventions. Melbourne: University of Melbourne; 2007.

17. Cheng Z, Lu Y, Cao Q, Qin L, Pan Z, Yan F, et al. Clinical features and chest CT manifestations of coronavirus disease 2019 (COVID-19) in a singlecenter study in Shanghai, China. Am J Roentgenol. 2020;215:121-6.

18. Rücker G, Schwarzer G, Carpenter JR, Schumacher M. Undue reliance on 12 in assessing heterogeneity may mislead. BMC Med Res Methodol. 2008;8(1):79.

19. Nyaga VN, Arbyn M, Aerts M. Metaprop: a Stata command to perform meta-analysis of binomial data. Arch Public Health. 2014;72(1):39.

20. Thompson SG, Sharp SJ. Explaining heterogeneity in meta-analysis: a comparison of methods. Stat Med. 1999;18(20):2693-708

21. Cochran WG. The comparison of percentages in matched samples. Biometrika. 1950:37(3/4):256-66

22. Egger M, Smith GD, Schneider M, Minder C. Bias in meta-analysis detected by a simple, graphical test. BMJ. 1997;315(7109):629-34. 
23. Jalali M, Abedi D. Prevalence of Listeria species in food products in Isfahan, Iran. Int J Food Microbiol. 2008;122(3):336-40.

24. Yücel N, Citak S, Önder M. Prevalence and antibiotic resistance of Listeria species in meat products in Ankara Turkey. Food Microbiol. 2005;22(2-3):241-5.

25. Yücel N, BALCI Ş. . Prevalence of Listeria, Aeromonas, and Vibrio species in fish used for human consumption in Turkey. J Food Prot. 2010;73(2):380-4

26. Akman D, Duran N, Diğrak M. Prevalence of Listeria species in ice creams sold in the cities of Kahramanmaraş and Adana. Turkish J Med Sci. 2004;34(4):257-62.

27. Chen J, Zhang X, Mei L, Jiang L, Fang W. Prevalence of Listeria in Chinese food products from 13 provinces between 2000 and 2007 and virulence characterization of Listeria monocytogenes isolates. Foodborne Pathog Dis. 2009;6(1):7-14.

28. Little C, Taylor F, Sagoo S, Gillespie I, Grant K, McLauchlin J. Prevalence and level of Listeria monocytogenes and other Listeria species in retail pre-packaged mixed vegetable salads in the UK. Food Microbiol. 2007;24(7-8):711-7.

29. Yakubu Y, Salihu M, Faleke O, Abubakar M, Magaji A, Junaidu A. Disinfectant effect of methylated ethanol against Listeria species. Vet World. 2012;5(2):91.

30. Zhu Q, Hussain M. Prevalence of Listeria species in fresh salad vege-tables and ready-to-eat foods Con-taining fresh produce marketed in canterbury, New Zealand. Adv Food Technol Nutr Sci Open J. 2014;1(1):5-9.

31. El-Malek AMA, Ali SFH, Hassanein R, Mohamed MA, Elsayh KI. Occurrence of Listeria species in meat, chicken products and human stools in Assiut city, Egypt with PCR use for rapid identification of Listeria monocytogenes. Vet World. 2010;3(8):353.

32. Rahimi E, Shakerian A, Raissy M. Prevalence of Listeria species in fresh and frozen fish and shrimp in Iran. Ann Microbiol. 2012;62(1):37-40.

33. Frye C, Donnelly CW. Comprehensive survey of pasteurized fluid milk produced in the United States reveals a low prevalence of Listeria monocytogenes. J Food Prot. 2005;68(5):973-9.

34. Jamali H, Paydar M, Ismail S, Looi CY, Wong WF, Radmehr B, et al. Prevalence, antimicrobial susceptibility and virulotyping of Listeria species and Listeria monocytogenes isolated from open-air fish markets. BMC Microbiol. 2015;15(1):144.

35. Stonsaovapak S, Boonyaratanakornkit M. Prevalence and antimicrobial resistance of Listeria species in food products in Bangkok, Thailand. J Food Saf. 2010;30(1):154-61.

36. Saltijeral JA, Alvarez VB, Garcia B. Presence of Listeria in Mexican cheeses. J Food Saf. 1999;19(4):241-7.

37. Ponniah J, Robin T, Paie MS, Radu S, Ghazali FM, Kqueen CY, et al. Listeria monocytogenes in raw salad vegetables sold at retail level in Malaysia. Food Control. 2010;21(5):774-8.

38. Osman KM, Samir A, Orabi A, Zolnikov TR. Confirmed low prevalence of Listeria mastitis in she-camel milk delivers a safe, alternative milk for human consumption. Acta Trop. 2014;130:1-6.

39. Rahimi E, Behzadnia A, Shakerian A, Momtaz H. Frequency of Listeria species from raw milk, traditional cheese and ice-cream in Shahrekord and Shiraz. J Microbial World. 2010;2:243-8.

40. Angelidis AS, Koutsoumanis K. Prevalence and concentration of Listeria monocytogenes in sliced ready-to-eat meat products in the Hellenic retail market. J Food Prot. 2006;69(4):938-42.

41. Zarei M, Maktabi S, Ghorbanpour M. Prevalence of Listeria monocytogenes, Vibrio parahaemolyticus, Staphylococcus aureus, and Salmonella spp. in seafood products using multiplex polymerase chain reaction. Foodborne Pathog Dis. 2012;9(2):108-12.

42. Nwaiwu O. An overview of Listeria species in Nigeria. Int Food Res J. 2015;22(2):455-64.

43. Yakubu Y, Salihu M, Faleke O, Abubakar M, Junaidu A, Magaji A, et al. Prevalence and antibiotic susceptibility of Listeria monocytogenes in raw milk from cattle herds within Sokoto Metropolis, Nigeria. Sokoto J Vet Sci. 2012;10(2):13-7.

44. Sarangi L, Panda H, Priyadarshini A, Sahoo S, Palai T, Ranabijuli S, et al. Prevalence of Listeria species in milk samples of cattle of Odisha. Indian J Comp Microbiol Immunol Infect Dis. 2009;30(2):135-6.

45. Shantha S, Gopal S. Prevalence of Listeria species in environment and milk samples. Adv Anim Vet Sci. 2014;2(5S):1-4.
46. Kovačević M, Burazin J, Pavlović H, Kopjar M, Piližota V. Prevalence and level of Listeria monocytogenes and other Listeria sp. in ready-to-eat minimally processed and refrigerated vegetables. World J Microbiol Biotechnol. 2013;29(4):707-12.

47. Bouayad L, Hamdi TM, Naim M, Leclercq A, Lecuit M. Prevalence of Listeria spp. and molecular characterization of Listeria monocytogenes isolates from broilers at the abattoir. Foodborne Pathog Dis. 2015;12(7):606-11.

48. Orsi RH, Wiedmann M. Characteristics and distribution of Listeria spp including Listeria species newly described since 2009. Appl microbiol Biotechnol. 2016;100(12):5273-87.

49. Dahshan H, Merwad A, Mohamed TS. Listeria species in broiler poultry farms: potential public health hazards. J Microbiol Biotechnol. 2016:26(9):1551-6.

50. Garedew L, Taddese A, Biru T, Nigatu S, Kebede E, Ejo M, et al. Prevalence and antimicrobial susceptibility profile of Listeria species from ready-to-eat foods of animal origin in Gondar Town, Ethiopia. BMC Microbiol. 2015:15(1):100

51. Seyoum ET, Woldetsadik DA, Mekonen TK, Gezahegn HA, Gebreyes WA. Prevalence of Listeria monocytogenes in raw bovine milk and milk products from central highlands of Ethiopia. J Infec Dev Ctries. 2015;9(11):1204-9.

52. Derra FA, Karlsmose S, Monga DP, Mache A, Svendsen CA, Félix B, et al. Occurrence of Listeria spp. in retail meat and dairy products in the area of Addis Ababa, Ethiopia. Foodborne Pathog Dis. 2013;10(6):577-9.

53. Gebretsadik S, Kassa T, Alemayehu H, Huruy K, Kebede N. Isolation and characterization of Listeria monocytogenes and other Listeria species in foods of animal origin in Addis Ababa, Ethiopia. J Infect Public Health. 2011:4(1):22-9.

54. Garedew-Kifelew L, Wondafrash N, Feleke A. Identification of drugresistant Salmonella from food handlers at the University of Gondar, Ethiopia. BMC Res Notes. 2014;7(1):545.

55. Hoy D, Brooks P, Woolf A, Blyth F, March L, Bain C, et al. Assessing risk of bias in prevalence studies: modification of an existing tool and evidence of interrater agreement. J Clin Epidemiol. 2012;65(9):934-9.

56. Dabboussi F, Alam S, Mallat H, Hlais S, Hamze M. Preliminary study on the prevalence of campylobacter in childhood diarrhoea in north Lebanon. EMHJ. 2012:18:1225-8.

57. Wong W, Pui C, Tunung R, Cheah Y, Nishibuchi M, Son R. Prevalence of Listeria monocytogenes in frozen burger patties in Malaysia. Int Food Res J. 2012;19:1756-61.

58. Cordano AM, Rocourt J. Occurrence of Listeria monocytogenes in food in Chile. Int J Food Microbial. 2001;70(1-2):175-8.

59. Mugampoza D, Muyanja CM, Ogwok P, Serunjogi M, Nasinyama G. Occurrence of Listeria monocytogenes in bulked raw milk and traditionally fermented dairy products in Uganda. Afr J Food Agric Nutr Dev. 2011. https://doi.org/10.4314/ajfand.v11i2.65916.

60. Morobe I, Obi C, Nyila MA, Gashe B, Matsheka M. Prevalence, antimicrobial resistance profiles of Listeria monocytognes from various foods in Gaborone, Botswana. Afr J Biotechnol. 2009. https://doi.org/10.5897/ AJB2009.000-9486.

61. Kunadu AP-H, Holmes M, Miller EL, Grant AJ. Microbiological quality and antimicrobial resistance characterization of Salmonella spp. in fresh milk value chains in Ghana. Int J Food Microbiol. 2018;277:41-9.

62. Little C, Roberts D, Youngs E, De Louvois J. Microbiological quality of retail imported unprepared whole lettuces: a PHLS food working group study. J Food Prot. 1999;62(4):325-8.

63. Yang H, Mokhtari A, Jaykus LA, Morales RA, Cates SC, Cowen P. Consumer phase risk assessment for Listeria monocytogenes in deli meats. Risk Anal Int J. 2006;26(1):89-103.

64. Molla B, Yilma R, Alemayehu D. Listeria monocytogenes and other Listeria species in retail meat and milk products in Addis Ababa, Ethiopia. Ethiop J Health Dev. 2004;18(3):208-12.

65. Morvan A, Moubareck C, Leclercq A, Hervé-Bazin M, Bremont S, Lecuit $M$, et al. Antimicrobial resistance of Listeria monocytogenes strains isolated from humans in France. Antimicrob Agents Chemother. 2010;54(6):2728-31.

66. Barbosa J, Magalhães R, Santos I, Ferreira V, Brandão TR, Silva J, et al. Evaluation of antibiotic resistance patterns of food and clinical Listeria monocytogenes isolates in Portugal. Foodborne Pathog Dis. 2013;10(10):861-6. 
67. Cabedo L, PicartiBarrot L, TeixidóiCanelles A. Prevalence of Listeria monocytogenes and Salmonella in ready-to-eat food in Catalonia, Spain. J Food Prot. 2008;71(4):855-9.

68. Beli E, Maçi R, Çoçoli S, Memoçi H. Frequency and characteristics of Listeria spp. in minced meat in Albanian retail market. Albanian J Agric Sci. 2014:525.

69. Dhanashree B, Otta S, Karunasagar I, Goebel W. Incidence of Listeria spp. in clinical and food samples in Mangalore India. Food Microbiol. 2003:20(4):447-53.

70. Uyttendaele M, Neyts K, Lips R, Debevere J. Incidence of Listeria monocytogenesin poultry and poultry products obtained from Belgian and French abbatoirs. Food Microbiol. 1997;14(4):339-45.

71. Malik S, Barbuddhe S, Chaudhari S. Listeric infections in humans and animals in the Indian subcontinent: a review. Trop Anim Health Prod. 2002;34(5):359-81.

72. Seçil A, Aydin F, Sümerkan AB. Molecular typing of Listeria spp. isolated from different sources. Ankara Üniversitesi Veteriner Fakültesi Dergisi. 2012:59(3):183-90.
73. Moshoeshoe SL. Incidence of Listeria monocytogenes in milk from producers in the Maseru area: [Bloemfontein?]: central university of technology, free state; 2013.

74. Peeler JT, Bunning VK. Hazard assessment of Listeria monocytogenes in the processing of bovine milk. J Food Prot. 1994;57(8):689-97.

75. Uhitil S, Jakšić S, PetrakT, Medić H, Gumhalter-Karolyi L. Prevalence of Listeria monocytogenes and the other Listeria spp. in cakes in Croatia. Food Control. 2004;15(3):213-6.

76. Ferron $\mathrm{P}$, Michard J. Distribution of Listeria spp. in confectioners' pastries from western France: comparison of enrichment methods. Int J Food Microbiol. 1993;18(4):289-303.

\section{Publisher's Note}

Springer Nature remains neutral with regard to jurisdictional claims in published maps and institutional affiliations.
Ready to submit your research? Choose BMC and benefit from:

- fast, convenient online submission

- thorough peer review by experienced researchers in your field

- rapid publication on acceptance

- support for research data, including large and complex data types

- gold Open Access which fosters wider collaboration and increased citations

- maximum visibility for your research: over $100 \mathrm{M}$ website views per year

At BMC, research is always in progress.

Learn more biomedcentral.com/submissions 